\title{
Non-Conventional Methods as a New Alternative for the Estimation of Terrestrial Biomass and Carbon Sequestered
}

\author{
Basam Dahy ${ }^{1}$, Salem Issa ${ }^{1 *}$, Taoufik Ksiksi ${ }^{2}$ and Nazmi Saleous ${ }^{3}$ \\ ${ }^{1}$ Department of Geosciences, UAEU, UAE \\ ${ }^{2}$ Department of Biology, UAEU, UAE \\ ${ }^{3}$ Department of Geography, UAEU, UAE
}

*Corresponding author: Salem Issa, Department of Geosciences, College of Science, UAEU, UAE.

Received Date: December 16, 2019

Published Date: December 18, 2019

\begin{abstract}
A practical definition of forest biomass is "the total amount of aboveground living organic matter in trees expressed as oven-dry tons per unit area". Terrestrial carbon sequestration is the process of storing atmospheric $\mathrm{CO} 2$ as carbon in the stems, roots of plants and in soil. Estimating of biomass can give an idea of the amount of carbon dioxide (CO2) that can be removed from the atmosphere by forests and plantations. Mapping, measuring and monitoring of biomass are now central issues due to the importance of biomass estimation in many ecology-related research areas. The estimation of biomass is a challenging task, especially in areas with both complex stands and varying environmental conditions, requiring accurate and consistent measurement methods. To efficiently and effectively estimate terrestrial biomass amount, it is important to have detailed knowledge of its distribution, abundance, and quality. Non-conventional approaches such as remote sensing (RS) and Geographic Information Systems (GIS) technologies offer the mean to enable rapid assessment of terrestrial biomass over large areas relatively quickly and at low cost. Indeed, RS and GIS have great potential in current estimation, future prediction and management of terrestrial carbon. In this regard, the deployment of an integrated RS / GIS solution for precision carbon management has high potential significance. This paper provides a mini review of biomass and carbon sequestered assessment using innovative non-conventional methods as compared to traditional conventional methods.
\end{abstract}

Keywords: Allometric equations; Soil organic carbon; Terrestrial carbon; Remote sensing; GIS

\section{Introduction}

Carbon sequestration is becoming an essential component in the fight against global warming. Forests act as large carbon pools where $\mathrm{CO}_{2}$ in the atmosphere is converted massively to biomass in the plant by photosynthesis process. Afforestation projects and land use conversion to forest (reforestation) can be used to earn carbon credits and reduce the carbon footprint, hence providing a longterm reduction in greenhouse gases (GHGs) levels through carbon sequestration [1]. This attitude has a growing interest among policymakers and governments [2]. Plantation cropping as a land use system has the potential to contribute to carbon stocks, maintain soil biodiversity and improve soil fertility [3]. Precise carbon stock estimation is a necessary step to define carbon emission mitigation strategies and programs at the local and regional level [4]. This kind of studies is necessary for a better understanding of the long-term behavior and drivers of carbon sequestration under different global climate change scenarios [5].
The total carbon stock in any terrestrial ecosystem is the sum of carbon in living biomass, dead biomass and soil [6]. Eggleston et al. [7] has listed five terrestrial ecosystem carbon pools involving biomass: above-ground biomass (AGB), below-ground biomass (BGB), litter, woody debris and soil organic matter [7]. Of these five, AGB is the most visible, dominant, dynamic and important pool of the terrestrial ecosystem. AGB contributes to atmospheric carbon fluxes to a much greater extent due to fire, logging, land use changes, etc., and so is of much greater interest. Therefore, it is necessary to keep monitoring it continuously not only a single date mapping. However, estimation of forest biomass rises scientific challenges to identifying feasible approaches to assess carbon at national level [8].

Traditional biomass assessment methods based on field measurements are the most accurate methods; however, they are difficult and unpractical to conduct over large areas and for 
broad-scale assessments [9]. These difficulties make monitoring activities more costly, time consuming, and labor intensive [10]. Recently, remote sensing (RS) procedures have been applied to natural resources management and biomass assessment. RS has the ability to obtain forest information over large areas with repetitive coverages, at reasonable cost and with acceptable accuracy. Moreover, the integration of remote sensing data into GIS models will benefit from both technologies; bringing ancillary and field data into the analysis and producing more reliable estimation of the AGB and carbon sequestered.

The aim of this study is twofold: (1) to review conventional methods for estimating forest biomass and carbon sequestered including destructive and non-destructive methods, and (2) to review non-conventional methods that use RS and GIS as innovative techniques applied to biomass studies and carbon assessment.

\section{Conventional Methods}

\section{Background}

These include direct (destructive) and indirect (nondestructive) methods. The direct method which is the most precise method for determining carbon biomass by destructively harvest all plants, partition each into various constituent components (e.g. stem, branches, leaves, flowers, fruits, roots) and subsequently determine the carbon content of the various components analytically OR calculated as a fraction of measured biomass (indirect) [9]. The destructive methods of biomass estimation are limited to a small area due to the destructive nature, time, expense and labor involved and sometime illegal especially for trees. In addition, these methods ultimately rely on ground measurement and can cause severe destruction to the forests as well as a risk of environmental deterioration $[10,11]$. The indirect methods include the estimation based on allometric equations (§ Allometric subsection) or through non-conventional methods using RS and GIS (§ non-conventional section).

Two routes for achieving sequestered carbon estimation: First, estimating soil organic carbon (SOC) which is part of soil organic matter (SOM). Second, estimating vegetation biomass which can be achieved by estimating the AGB and then deriving the remaining components; BGB, Litter and Debris, from the AGB as shown in (Table 1). The most common way for estimating SOM is through soil sampling at various layers and then, the SOC is estimated using total combustion method, as explained by Walkley \& Black [12]. The content of SOC included in SOM may change depending on many factors (ecosystems, type of organic residues and land management, etc.). Many studies estimate SOC from SOM using the conventional factor of 1.724 ( $\sim 58 \%$ of SOM). This figure is widely used and has appeared in many studies and published papers in the last century; while Brady \& Weil [13] concluded that this value (58\% of SOM) probably applies only to highly stabilized humus [13]. After his statistical analysis of 481 studies, Pribyl [14] found that conventional factor varies from 1.35 to 7.50 with a mean value of 2.20, concluding that any single-number conversion factor, universally applied, has the potential for serious error when used to estimate the carbon content of soils [14]. However, recent studies have accepted a generic quick, simple and inexpensive coefficient of $57 \%$ for measuring SOM as percent of SOM [15].

Table 1: Calculation methods of stored carbon components in terrestrial ecosystems.

\begin{tabular}{|c|c|c|c|}
\hline No & Component & Stored C Calculation Method & Source \\
\hline 1 & AGB & Destructive OR Non-destructive Methods & {$[8]$} \\
\hline 2 & BGB & $20 \%$ of AGB & {$[16]$} \\
\hline 3 & Litters & $10-20 \%$ of AGB & {$[17]$} \\
\hline 4 & Debris & Total combustion method & {$[12]$} \\
\hline 5 & SOC & & \\
\hline
\end{tabular}

Where AGB is above ground biomass, BGB is below ground biomass (root biomass), SOC is soil organic carbon, and SOM is soil organic matter.

\section{Allometric Biomass Equations}

The main objective in developing allometric equations is to avoid destructing forests when estimating their biomass and provide a cost effective and environment-friendly option since it is done without harvesting [18]. In general, allometric equation is a statistical model to estimate the biomass of the trees using their biometrical characteristics which are non-destructive and simpler to measure. Therefore, nondestructive methods through allometric relationships are increasingly used. Such equations have also been proven to be fast, inexpensive, and more suitable for largescale estimation of forest carbon stocks [6]. Allometric models are commonly used in forest inventories and ecological studies [18]. The models relate biomass of an entire tree or individual tree components (e.g., stems, branches, leaves or roots) to one or more easily tree variables and dendrometric measures (e.g. height, diameter breast height or crown size) [19]. The proportions between height and diameter, between crown height and diameter, between biomass and diameter follow rules that are common to all trees that are grown under the same conditions; and become more useful in uniform forests or plantations with similar aged stands [20]. The selection of appropriate and robust models, therefore, have considerable influence on the accuracy of estimates obtained [21]. It is worth to mention that the goal of using allometric equations is estimating biomass without the need to cut trees, but the equations must be based on destructive sampling of vegetation somewhere before they can be applied generally and they still need to be validated which requires cutting and weighting some trees components [9]. The number of trees destructively sampled to build allometric equations differ from one study to another. Currently, there is no consensus on the number of trees that should be sampled, as this is often dependent on resource availability and permission to harvest trees [9]. For example, Russell [24] and Deans et al. [25] used 15 and 14 trees, while Brown et al. [22] and Khalid et al. [23] used only 8 and 10 trees, respectively; to build their allometric equations [22-25]. In their study of oil palm plantations of Benin forests, Aholoukpè et al. [26] used 25 palms from several ages and different genetic origins to build a species specific allometric equation [26]. However, recent study showed that small sample size yield biased allometric equations [27]. 
Generally, there is no specific procedure to build allometric equations yet there is a recommended guideline for documenting allometric equations [28]. Jara et al. [28] recommended that researchers should only report all the details in methods section of how they build up their equations. Furthermore, sampled trees should be randomly selected, regardless of health condition or degree of damage, because sampling only trees with fully intact structural characteristics will likely result in an equation that overestimates biomass for the general case. In this respect, data outliers should not be removed simply to improve model fit metrics [9]. There are many existent allometric equations. For example, the GlobeAllomeTree database contains over 706 equations from Europe, 2843 from North America and 1058 from Africa [29]. Some are volume equations, while others are biomass equations. According to the Brown \& Lugo (1992) method, the biomass can be calculated from volume of the biomass per hectare (VOB/ha) by using a generalized volume model, wood density and a biomass expansion factor [21]. One of the limitations of volume equations is that it can only be applied to stem while biomass equations cover a wide range of vegetation components [30]. Allometric models can be developed for individual species or multiple species (mixture of species) to represent a community or bioregion and can be developed to cover specific sites, regional or pan-tropical scales $[9,21]$. The multi-species equations built because it is practically difficult to develop allometric equations for all species present in the ecosystem [31]. For example, in their work in tropics, Chave et al. [32] has shown that one hectare of tropical forest may shelter as many as 300 different tree species [32]. So, the multi-species allometric models offer methodological efficiencies for biomass estimation compared to those developed for individual species at specific locations. However, they have the potential to misrepresent local, species- or community-specific variations and anomalies, and therefore can lead to increased error and fail to capture both variations in forest type and diversity of the natural vegetation communities [21]. Therefore, tailored equations designed for specific species are needed for more accurate biomass estimation. Such equation is still conditioned by the ecological zone where the equation had been built. Hence weakening the estimation's accuracy of the actual forest AGB when the equation is used in another area or region [33]. Due to the different characteristics of plant species from site to site, preexisting equations developed at locations that are different from the one in consideration may have limited applicability, even if the equation is species-specific $[9,10]$. In their review of allometric equations in Asia, Yuen et al., (2016) concluded that applying existing allometric equations out of convenience is potentially a key source of uncertainty in above- and below-ground carbon stock estimates in many Asian landscapes [9]. The selection of allometric equations can influence local, regional and global biomass estimates, therefore, there is an importance of site-specific equations for accurate estimation of biomass as generalized equations can overestimate AGB by $50 \%$ to $65 \%$ [11]. The locally developed models are expected to provide less uncertainty than generic equations [34]. Site and species specific allometric models should logically provide a greater level of accuracy at a given location to assist the assessment of biomass carbon sequestration and that make the locally built equation a better option to produce more accurate site-specific biomass estimation [11]. Finally, since the choice of the equations is the first critical step, there has been a rapid increase in efforts to develop locally appropriate equations [29].

The mathematical model commonly used for modeling aboveground biomass is based on the power function [9]. This was founded on the basis that the growth of a plant is characterized by the relation of proportionality between its total biomass and its size [35]. Biometric variables measured in plant species were considered as independent variables (diameter breast height, total height, crown variables, stem height, etc) and incorporated into a power function model [36]. The allometry based on power model have good reliability as indicated by high coefficient of determination indices [37]. Researchers involved in the development and application of biomass allometric equations are faced with many challenges. One of them is the choice between simple bivariate power-law (typical allometric) functions and models with multiple predictors [29]. Different variables (structural and non-structural) were considered when building biomass allometric equations. Most equations for above-ground biomass, or biomass of any component (stem, branch, leaves, other) use equations with diameter and/or height as independent variables. Other variables such as girth, basal area and crown dimensions have been used even less frequentlyusually in special cases [9]. Using wood density, when it is available, as a predictor is considered as significantly improving the biomass prediction equation when dealing with multispecies dataset [32]. In their study to investigate the allometric equations in China, Cheng et al. [30] found that the most frequently used predictive variable in single-variable models is diameter at breast height (DBH), and in two-variable models are DBH and tree height while wood density and crown diameter are presented in more complicated models [30]. They found that diameter variables have a dominant proportion of $87.4 \%$ of the surveyed equations. However, DBH showed a weak correlation with biomass quantity in specific species, like palm for example [38,39]. Age as a predictor used in estimating the biomass in many studies as there is a linear correlation between age and biomass accumulation [1,40-42]. Many studies have highlighted the importance of tree height as predictor variable in the aboveground biomass equation $[3,10,19,35]$. Crown variables as indicators for biomass estimation became more interesting as a result of improving RS technologies. Furthermore, more than one allometric equation can be developed for each plant species. The reasons behind that can be: (1) difference in ecoregion sites that these equations developed for (Tropical or Amazonian forests ..etc), (2) the decision of the developers of the allometric equations and choosing of the suitable variable/s (height, DBH, trunk height, etc.) to work as input (independent variable) to the model, (3) the use of the allometric equations to cover either specific parts of the plant (AGB, crown biomass, trunk biomass, etc.) or specific age (young, mature, mixed, etc.), and (4) the selection of the mathematical equation form (power, linear, algorithmic, etc.). Finally, more 
recently, allometric equations have been used, coupled with remote sensing (RS) and field-based structural variables measurements $[35,43]$. For example, Cheng et al. [30] recommended to develop more equations with different field structural variables that can be linked to RS predictors [30]. Likewise, Jucker et al. [44] suggested in their review of allometric equations to develop a new generation of allometric equations that estimate biomass based on attributes which can be remotely sensed [44].

\section{Non-Conventional Methods}

\section{Background}

Non-conventional methods that used RSand related technologies such as GIS have proved to be practical and cost/time effective. During the preparation of this review, 156 articles related to AGB estimation by non-conventional methods, were covered (Figure 1). Three quarters of these used optical sensors (with different spatial resolutions) and the remaining quarter used active sensors (almost equally between RADAR and LiDAR sensors). For optical sensors, half of these studies used coarse spatial resolution ( $>100$ meter) like MODIS and SPOT VEG sensors. Around one third of studies that used optical sensors estimated the biomass by moderate spatial resolution ( $\sim 10-100$ meter) like Landsat, IRS, and SPOT sensors while around $20 \%$ of the studies used fine spatial resolution data (submeter to 5 meter) like IKONOS, Quickbird and World View sensors. RS can provide data over large areas at a fraction of the cost associated with extensive field works and enables access to inaccessible places. Data from RS satellites are available at various scales, from local to global, and from several different platforms. There are also different types of data both Passive, such as optical and thermal remote sensing sensors, or Active, such as Radar and LiDAR sensors, with each has its own advantages and disadvantages [45]. On the other hand, GIS is a platform hosting spatial databases capable of assembling and integrating geographically referenced data, running spatial analysis, integrating various types and formats of spatial data, building spatial models enabling the prediction of future scenarios, and allowing for good management of forests. The estimation and modelling of carbon sequestered using RS and GIS methods is receiving an increasing attention and usage due to the multiple benefits they offer to scientists. To improve the accuracy of estimating AGB, integration of more than one sensor is becoming a trend as well as the integration with GIS-based approaches. More than 46 articles were reviewed that integrated both approaches. The trend is increasing in order to improve the accuracy of AGB estimates in plant species levels, instead of forests in general or mixed species.

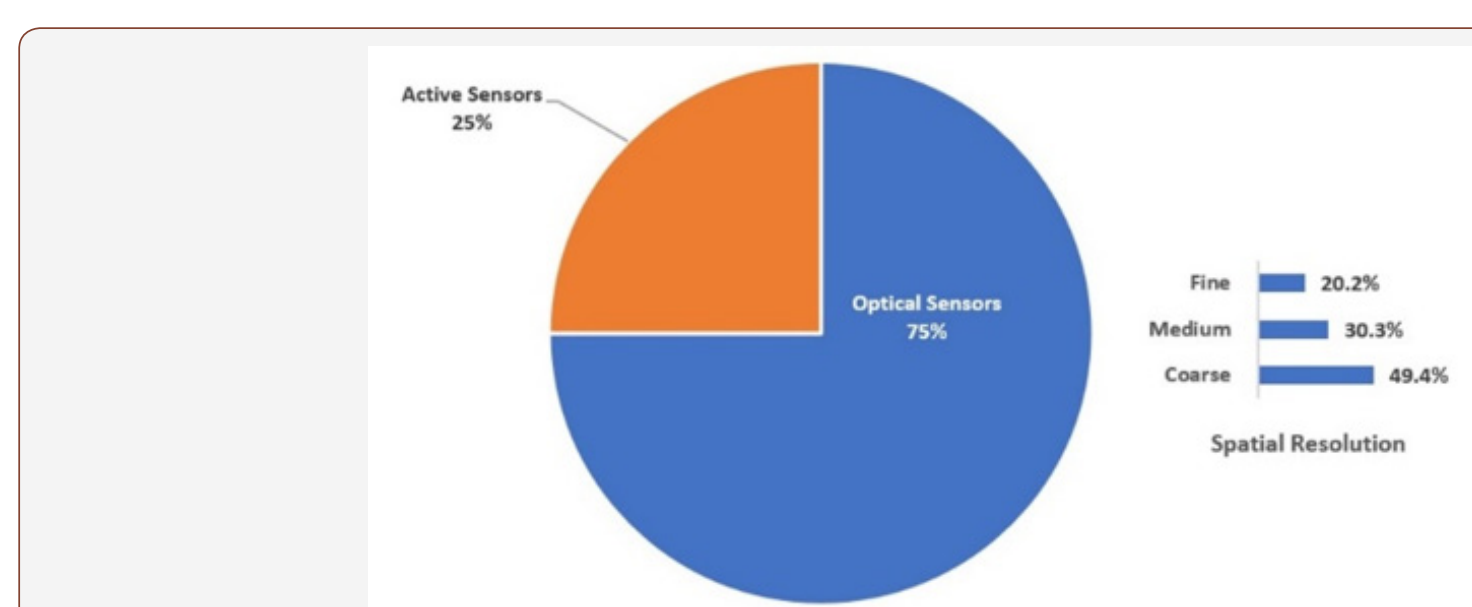

Figure 1: Data types used in AGB estimation using non-conventional methods in 156 studies were covered in this review since 1984.

Although RS proved efficient in saving time and money however, this technology cannot achieve its goal without additional field and data measurement. Nevertheless, the amount of fieldwork required with RS is largely reduced. This should not lead to totally reject traditional methods in estimation AGB, rather taking the advantages of non-conventional methods to accelerate and enhance existing methods through process integration and modelling [46]. RS data are used as input data to GIS, where GIS is then used as a spatial platform for data layering and database building to perform spatial data analysis and map creation. Not only does this save time but also allows for faster and better communication between research centers across the globe [47].

\section{Remote Sensing data types for estimating AGB}

RS-based approaches have become popular due to their unique characteristics in data collection and presentation that can detect spatial variability, spatial distributions, patterns of forests and estimate their changes over time [48]. To address this methodological issue and provide biomass information in different environments, different techniques and sensors have been applied and tested. RS, both active and passive, provide some of the most time-efficient and cost-effective approaches to derive AGB estimation at regional and national scale. Optical, RADAR, and light detection and ranging (LiDAR) data have been extensively used to estimate AGB with a variety of methods [4]. Despite the successful application of any sensors in AGB estimation, there are challenges related to acquisition costs, area coverage (swath width), and limited availability. RS data are nowadays abundant and widely available for a fraction of the cost required only a decade ago. For example, archived and recent Landsat imageries are available and are freely downloadable from USGS website providing a globally consistent record from 1972; other resources are being published and added to the internet. Furthermore, these data are 
captured with various, radiometric, spectral, spatial and temporal resolutions, hence meeting the needs for AGB detection, mapping and assessment. Selecting the "right" sensor is associated with the specific data availability of the area under study, project budget, technical skill requirements for data interpretation and software packages. The resolutions of the sensors used are pre-defined to meet the researcher's needs and specifications, although it happens that a specific sensor's data are the only available for a study area. Many software packages can perform digital images processing and spatial analysis like ERDAS imagine, ENVI, ArcGIS and other open source software. These packages are relatively easy to use and can produce exceptional results.

\section{Optical sensors}

Table 2: A summary of limitations and benefits of Optical, RADAR, and LiDAR sensors used for estimating the Above Ground Biomass (AGB) of standing forests.

\begin{tabular}{|c|c|c|c|}
\hline Sensor Types & Approaches/ Resolutions & Limitations & Benefits \\
\hline \multirow{16}{*}{ Optical Sensors } & \multirow{7}{*}{$\begin{array}{c}\text { Course Resolution Spatial }(>100 \mathrm{~m}) \text { Examples: } \\
\text { MODIS, AVHRR, NOAA, METEOSAT and SPOT } \\
\text { Vegetation }\end{array}$} & $\begin{array}{l}\text { - Average R value } 0.58 \text { with average } \\
\text { predictive error equal } 42 \%\end{array}$ & $\begin{array}{l}\text { - Availability of data with huge } \\
\text { datasets archived }\end{array}$ \\
\hline & & $\begin{array}{l}\text { - Saturation of spectral data at high } \\
\text { biomass density }\end{array}$ & $\begin{array}{l}\text { - Estimation and mapping of AGB } \\
\text { at continental and global scale }\end{array}$ \\
\hline & & $\begin{array}{l}\text { - Mismatch between the size of } \\
\text { field plots, field measurements and } \\
\text { pixel size (mixed pixels) }\end{array}$ & $\begin{array}{l}\text {-Repetitive with high temporal } \\
\text { frequency increasing the proba- } \\
\text { bility of acquiring cloud-free data }\end{array}$ \\
\hline & & - Clouds cover & - Provide consistent spatial data \\
\hline & & $\begin{array}{l}\text { - Limited to discriminate vegeta- } \\
\text { tion structure }\end{array}$ & - Cost effective (FREE) \\
\hline & & $\begin{array}{l}\text { - Average R value } 0.68 \text { with average } \\
\text { predictive error equal } 32 \%\end{array}$ & -Provide global consistent data \\
\hline & & $\begin{array}{l}\text { - Single pixel can encompass many } \\
\text { tree crown or non-crown feature }\end{array}$ & $\begin{array}{l}\text { - Archived datasets back to } 1972 \\
\text { for Landsat }\end{array}$ \\
\hline & \multirow{2}{*}{$\begin{array}{l}\text { Medium Spatial Resolution }(10-100 \text { m) Examples: } \\
\text { TM Landsat, ETM+, OLI and SPOT }\end{array}$} & $\begin{array}{l}\text { - Nonreliable indicators of biomass } \\
\text { in closed canopy structure }\end{array}$ & - Small to large-scale mapping \\
\hline & & $\begin{array}{l}\text { - Not all texture measure can effec- } \\
\text { tively extract biomass information }\end{array}$ & - Low / Free costs \\
\hline & \multirow{3}{*}{$\begin{array}{l}\text { Fine Spatial Resolution }(<5 \mathrm{~m}) \text { Examples: Quick } \\
\text { bird, WorldView-2, and IKONOS }\end{array}$} & $\begin{array}{l}\text { - Need large data storage and pro- } \\
\text { cessing time }\end{array}$ & $\begin{array}{l}\text { - Average } R \text { value } 0.75 \text { and aver- } \\
\text { age predictive error }(27 \%)\end{array}$ \\
\hline & & $\begin{array}{l}\text { - More expensive when it applies } \\
\text { on large areas }\end{array}$ & - Estimate tree crown size \\
\hline & & - High cost & -Validation at localized scale \\
\hline & \multirow{4}{*}{$\begin{array}{c}\text { Hyperspectral Many, very narrow, and contiguous } \\
\text { spectral bands Examples: AISA Eagle, HYDICE and } \\
\text { ALOS }\end{array}$} & -Clouds cover & -Average $\mathrm{R}$ value 0.83 \\
\hline & & -High cost & $\begin{array}{l}\text {-Allows discrimination of subtler } \\
\text { differences (species level) }\end{array}$ \\
\hline & & $\begin{array}{l}\text {-Suffer from band redundancy and } \\
\text { saturation in dense canopy }\end{array}$ & $\begin{array}{l}\text {-Potentiality for the future of RS- } \\
\text { based biomass estimation models }\end{array}$ \\
\hline & & $\begin{array}{l}\text {-Computationally intensive and } \\
\text { technically demanding }\end{array}$ & $\begin{array}{l}\text {-Integration with LiDAR can } \\
\text { improve results. }\end{array}$ \\
\hline \multirow{6}{*}{ RADAR Sensors } & \multirow{6}{*}{$\begin{array}{l}\text { Approaches involve the use of either backscatter } \\
\text { values or interferometry techniques Examples: } \\
\text { Microwave/radar i.e. ALOS PALSAR, ERS-1, Envisat } \\
\text { and JERS-1. }\end{array}$} & $\begin{array}{l}\text {-Not accurate in mountainous } \\
\text { region due to spurious relation be- } \\
\text { tween AGB and backscatter values. }\end{array}$ & -Measure forest vertical structure \\
\hline & & $\begin{array}{c}\text {-Signal saturation in mature forests } \\
\text { at various wavelengths ( } \mathrm{C}, \mathrm{L} \text { and } \mathrm{P} \\
\text { bands) }\end{array}$ & -Generally free \\
\hline & & $\begin{array}{l}\text {-Polarizations (e.g., HV and VV) } \\
\text { problems }\end{array}$ & $\begin{array}{c}\text {-Can be accurate for young and } \\
\text { sparse forest }\end{array}$ \\
\hline & & $\begin{array}{l}\text {-Low spatial resolution makes it } \\
\text { inaccurate for AGB assessment at } \\
\text { the species level. }\end{array}$ & -Repetitive data \\
\hline & & $\begin{array}{l}\text {-Cannot be applied on any vege- } \\
\text { tation type without taking note of } \\
\text { stand characteristics and ground } \\
\text { conditions. }\end{array}$ & $\begin{array}{c}\text { Can give an average } R \text { value equal } \\
0.74 \text { with average predictive error } \\
\text { equal } 25 \% \text {. }\end{array}$ \\
\hline & & & $\begin{array}{l}\text { Integrating RADAR with multi } \\
\text { source data (optical, microwave } \\
\text { data and GIS modeling tech- } \\
\text { niques) is a promising approach. }\end{array}$ \\
\hline
\end{tabular}




\begin{tabular}{|c|c|c|c|}
\hline \multirow{5}{*}{ LiDAR Sensors } & \multirow{5}{*}{$\begin{array}{c}\text { Using laser light Spatial Resolution: }(0.5 \mathrm{~cm}-5 \mathrm{~m}) \\
\text { Examples: Carbon 3-D }\end{array}$} & $\begin{array}{l}\text { - Repetitive at high cost and logis- } \\
\text { tics deployment }\end{array}$ & $\begin{array}{l}\text {-Penetrate cloud cover and } \\
\text { canopy }\end{array}$ \\
\hline & & $\begin{array}{l}\text {-Requires extensive field data } \\
\text { calibration }\end{array}$ & $\begin{array}{l}\text {-Among all sensors option, LiDAR } \\
\text { is the easiest in extraction tree } \\
\text { attributes for estimation AGB with } \\
\text { great accuracy }\end{array}$ \\
\hline & & -Highly expensive & $\begin{array}{l}\text {-Accurate for estimating forest } \\
\text { biomass in all spatial variability } \\
\text { (sparse, young or mature forests) }\end{array}$ \\
\hline & & -Technically demanding & $\begin{array}{c}\text {-The Average } \mathrm{R} \text { value is equal } 0.89 \\
\text { with average predictive error } \\
\text { equal } 14 \%\end{array}$ \\
\hline & & & $\begin{array}{l}\text {-Potentiality for satellite-based } \\
\text { system to estimate global forest } \\
\text { carbon stock }\end{array}$ \\
\hline
\end{tabular}

Optical sensors, sometimes called passive sensors, are RS systems relying on visible and reflected infrared light. These sensors record solar radiation reflected by vegetation canopies, which is empirically related to biomass. The passiveness of optical sensors limits its ability to penetrate clouds cover and misestimating of AGB. However, the optical imagery-based technologies are commonly used for biomass estimation due to high correlations between spectral bands and biomass [48]. Their radiometry is influenced by the vegetation structure, texture and shadow and thus indirectly correlated with AGB [49]. Near infrared band, in general, is the most prominent band in separating tree crowns from background by giving the highest contrast consistently [50]. Optical sensors vary in their spectral resolutions (multispectral/ hyperspectral sensors), spatial, radiometric and temporal resolutions and have their successes and limitations (Table 2).

\section{Active sensors (RADAR and LiDAR)}

Active sensors are the sensors that emit and record backscatter valuesorinterferometrytechniqueina portion of the electromagnetic spectrum [51]. Two methods usable in the quantification of carbon sequestration because of their capabilities and functionalities in measuring changes in biomass. They are Synthetic-aperture radar (SAR) which depend on microwave backscattered values and Light Detection and Ranging (LiDAR) which emit and record laser light (near-infrared) [51]. Many studies showed the ability of active sensors to estimate forest biomass more accurately than optical sensors [52,53]. The most important advantage of active sensors in studying the biomass is that its signals can measure forest vertical structure and it does not saturate in biomass densities compared with the optical sensors.

RADAR RS has gained importance for AGB estimation in recent years due to its cloud penetration ability as well as vegetation structural information that can be collected through RADAR sensors [45]. While airborne RADAR systems have been operating for many years, space-borne systems such as Terra-SAR, ALOS and PALSAR have become available since 2000 [54]. This has enabled repetitiveness and cost-effectiveness. The benefits associated with RADAR in the process of quantifying carbon sequestration is the fact that its signals are not hindered by tree canopies and thus its capabilities of obtaining the required data even in regions with dense forest canopies [55]. It can measure forests vertical structure and can penetrate vegetation to different degrees and provides information on the amount and three-dimensional (3D) distribution of structures within the vegetation [45]. Table 2 summarizes the limitations and benefits of RADAR sensors for AGB estimation studies.

LiDAR is a relatively new technology and is promising in biomass estimation. Especially its power in sampling the vertical distribution of canopy and ground surfaces, hence providing detailed structural information about vegetation. Consequently, estimations of basal area, crown size, tree height and stem volume are done more accurately. A number of studies have built strong correlations between LiDAR parameters and AGB [56-64]. LiDAR is either airborne or the technique can also be achieved on land [65]. Because of its high resolution, it can carry out measurements penetrating even the densest canopies to a point of interest beneath the forest cover. LiDAR is currently the most accurate sensor technology to estimate forest structure. Table 2 summarizes its main limitations and benefits.

\section{Conclusion and Recommendations}

This study is the result of consensus of thousands of scientific papers over the last five decades. Estimation of AGB and monitoring, modeling and management of carbon sequestration using nonconventional methods such as RS and GIS proved to be practical and feasible and provide an adequate validation and accuracy assessment approach. These innovative methods can provide a practical alternative especially for developing countries, which lack accurate maps, for measuring, mapping, monitoring, modeling and management of their carbon stock in biomass and soil. This will certainly lead to soil productivity, plant productivity, food security and the implementation of land degradation protocols.

The different scenarios practiced in estimation of forest biomass have their advantages and disadvantages. The fieldwork measurements method is the most accurate but need a lot of time, expense and labor. Building allometric equations can avoid the destructive aspect of the fieldwork's method as well as all its disadvantages. Unfortunately, most of allometric equations are developed for mixed species and not a tailored equation for a specific species. Furthermore, with the advent of new technologies 
such as remote sensing and GIS, it becomes necessary to build new allometric equations that are integrable to and correlated with remote sensing variables, for example, crown and height attributes. Building databases that provide researchers and decision makers with information about the rate of carbon sequestered and stored by each plant species, especially those that have economic value, will fill the gap and increase our understanding of the potentiality of plant species and ecosystems types for sequestering atmospheric carbon.

Nonetheless, RS alone is not sufficient, as soil samples and verification of results by ground truthing, are required in some stages in any estimation of biomass researches. The best fit methodology relies on both fieldwork as well as analysis of RS data. Measuring forest biomass remotely and consistently over large areas greatly varies with the type of instrument and the platform. However, these difficulties could be overcome by using different sensors options, innovative methods and avoiding the limitations that relate to many aspects like scale, technical, costs, error associated \& uncertainties. High spectral, spatial and temporal resolution RS data and active sensors, like RADAR and LiDAR, are preferred, however, moderate resolution satellite and free data, like Landsat for example, is effective to estimate the biomass, hence the carbon stock and estimate the historical conditions of a forest. Developing algorithms that combine more than one remote sensor is highly important to tackle the estimation of AGB in order to estimate carbon sequestration. Merging and fusion techniques of more than one data has the potential to reduce uncertainty errors in biomass estimation. In AGB estimation studies, it is important to consider the effects of bioclimatic factors depending on parameters like plant age, species, forest type, rainfall, topography, vegetation structural variations, heterogeneity of landscapes, and seasonality. One of the common challenges to achieve this is to map the spatial pattern of vegetation and soil carbon and produce geo-referenced estimates of carbon to give a better understanding of carbon dynamics and quantify the regional and global carbon budget. In addition, it provides a strong knowledge to decision makers to identify where is the most essential to be focused on.

The field-based measurement and non-conventional methods introduced has the potential to help improve carbon estimation to reduce emissions resulting from deforestation and forest degradation. Therefore, it can be applied to enhance the decisionmaking process on sustainable monitoring and management of carbon sequestration like afforestation, reforestation, and forest conservation projects.

\section{Acknowledgement}

None.

\section{Conflict of Interest}

No conflict of interest.

\section{References}

1. SL Singh, UK Sahoo, A Kenye, A Gogoi (2018) Journal of Environmental Protection 9: 912.
2. A Baral, GS Guha (2004) Trees for carbon sequestration or fossil fuel substitution: the issue of cost vs. carbon benefit. Biomass and Bioenergy 27: 41-55.

3. C Prayogo, RR Sari, DH Asmara, S Rahayu, K Hairiah (2018) AGRIVITA, Journal of Agricultural Science 40.

4. N Clerici, K Rubiano, A Abd Elrahman, JM Posada Hoestettler, et al. (2016) Estimating Aboveground Biomass and Carbon Stocks in Periurban Andean Secondary Forests Using Very High Resolution Imagery. Forests 7(7): 138

5. RO Corona Núñez, J Campo, M Williams (2018) Forest Ecology and Management 409: 202.

6. J Koala, L Sawadogo, P Savadogo, E Aynekulu, J Heiskanen, et al. (2017) Allometric equations for below-ground biomass of four key woody species in West African savanna-woodlands. Silva Fennica 51(3).

7. HS Eggleston, L Buendia, K Miwa, T Ngara, K Tanabe (2006) Institute for Global Environmental Strategies. Hayama, Japan 2: 48.

8. HK Gibbs, S Brown, JO Niles, and J A Foley (2007) Monitoring and estimating tropical forest carbon stocks: making REDD a reality. Environmental Research Letters 2: 045023

9. JQ Yuen, T Fung, and AD Ziegler (2016) Forest Ecology and Management 360: 323.

10. N Khalid, JRA Hamid (2017) Of 4: 2.

11. SI Maulana, Y Wibisono, and S Utomo (2016) Indonesian Journal of Forestry Research 3: 107.

12. A Walkley and IA Black (1934) Soil Science 37: 29.

13. NC Brady, RR Weil (2010) The Nature and Properties of Soil $12^{\text {th }}$ Ed (Prentice Hall Inc Upper Saddle River, New Jersey, 1999).

14. DW Pribyl (2010) Geoderma 156: 75.

15. R Ponce Hernandez, P Koohafkan, J Antoine (2004) Assessing Carbon Stocks and Modelling Win Win Scenarios of Carbon Sequestration through Land Use Changes, Food \& Agriculture Org.

16. MA Cairns, S Brown, EH Helmer, GA Baumgardner (1997) Root biomass allocation in the world's upland forests. Oecologia 111: 1-11.

17. RA Houghton, F Hall, SJ Goetz (2009) Importance of biomass in the global carbon cycle. Journal of Geophysical Research: Biogeosciences 114.

18. S Brown, AJ Gillespie, AE Lugo (1989) Forest Science 35: 881.

19. N Picard, L Saint André, M Henry (2012) Manual for building tree volumeand biomass allometric equations. From field measurement to prediction, pp. 1-207.

20. L Kumar, O Mutanga (2017) Remote Sensing of Above-Ground Biomass. Remote Sensing 9(9): 935.

21. H Mahmood, MR Siddique, L Costello, L Birigazzi, SR Abdullah, et al. (2019) IForest Biogeosciences and Forestry 12(1): 69-75.

22. IF Brown, LA Martinelli, WW Thomas, MZ Moreira, CC Ferreira, et al. (1995) Forest Ecology and Management 75: 175.

23. H Khalid, ZZ Zin, JM Anderson (1999) Quantification of Oil Palm Biomass and Nutrient Value in a Mature Plantation I: Above Ground Biomass. Journal of Oil Palm Research 11: 23-32.

24. CE Russell (1983) Nutrient Cycling and Productivity of Native and Plantation Forests at Jari Florestal. Para, Brazil, University of Georgia $19(4)$.

25. JD Deans, J Moran, J Grace (1996) Biomass relationships for tree species in regenerating semi-deciduous tropical moist forest in Cameroon. Forest Ecology and Management 88(3): 215-225.

26. H Aholoukpé, B Dubos, A Flori, P Deleporte, G Amadji, et al. (2015) Scientific Reports 5: 17153.

27. L Duncanson, O Rourke, R Dubayah (2015) Scientific Reports 5: 17153.

28. MC Jara, M Henry, M Réjou Méchain, C Wayson, M Zapata Cuartas, et al. (2015) Annals of Forest Science 72: 763. 
29. GW Sileshi (2014) Forest Ecology and Management 329: 237.

30. Z Cheng, JGP Gamarra, L Birigazzi (2014) Inventory of Allometric Equations for Estimation Tree Biomass a Database for China Rome, Italy: UNREDD Programme.

31. WN Dick OB (2015) Forest Research: Open Access 04.

32. J Chave, C Andalo, S Brown, MA Cairns, JQ Chambers, et al. (2005) Oecologia 145: 87.

33. M Segura, M Kanninen (2005) Biotropica 37: 2.

34. M Cifuentes Jara, M Henry, M Réjou Méchain, C Wayson, M Zapata Cuartas, et al. (2015) Guidelines for documenting and reportingtree allometric equations. Annals of Forest Science 72: 763.

35. NH Fonton, V Medjibé, A Djomo, J Kondaoulé, V Rossi, et al. (2017) Open Journal of Forestry 7: 388.

36. F Da Silva, R Suwa, T Kajimoto, M Ishizuka, N Higuchi, N Kunert (2015) Allometric Equations for Estimating Biomass of Euterpe precatoria, the Most Abundant Palm Species in the Amazon. Forests 6: 450.

37. D Gevana, S Im (2016) Malaysian Forester 79: 39.

38. M Sajdak, B Velázquez Martí, I López Cortés (2014) Renewable Energy 71: 545 .

39. RS Carlos, Peacute llico Netto Sylvio, PDC Ana, Lccedilo R Aureacutelio, B Alexandre, et al. (2015) African Journal of Agricultural Research 10: 4067.

40. J Mc Morrow (2001) International Journal of Remote Sensing 22: 2243.

41. IE Henson, KC Chang (2003) in Proceedings of the PIPOC 2003 International Palm Oil Congress, Malaysian Palm Oil Board, pp: 960-974.

42. RHV Corley, PBH Tinker (2008) The Oil Palm (John Wiley \& Sons).

43. S Issa, B Dahy, N Saleous, T Ksiksi (2019) International Journal of Remote Sensing, 1.

44. T Jucker, J Caspersen, J Chave, C Antin, N Barbier, et al. (2017) Allometric equations for integrating remote sensing imagery into forest monitoring programmes. Global Change Biology 23(1): 177.

45. L Kumar, P Sinha, S Taylor, AF Alqurashi (2015) Review of the use of remote sensing for biomass estimation to support renewable energy generation. Journal of Applied Remote Sensing 9: 097696.

46. B Tsitsi, Dubetimothy, Mutangaonisimo, Shoko Cletah, Samuel Adelabu, (2016) Remote sensing of aboveground forest biomass: A review. Tropical Ecology 57: 125.

47. S Deng, Y Shi, Y Jin, L Wang (2011) Energy Procedia 5: 1535.

48. P Zhao, D Lu, G Wang, C Wu, Y Huang, S Yu (2016) Imagery and Corresponding Solutions to Improve Forest Aboveground Biomass Estimation. Remote Sensing 8: 469.
49. C Eisfelder, C Kuenzer, S Dech (2012) International Journal of Remote Sensing 33: 2937.

50. HZ Shafri, N Hamdan, MI Saripan (2011) International Journal of Remote Sensing 32: 2095

51. N Ghasemi, M R Sahebi, and A Mohammadzadeh (2011) International Journal of Geomatics and Geosciences 1: 776.

52. MA Lefsky, WB Cohen, GG Parker, DJ Harding (2002) Lidar Remote Sensing for Ecosystem Studies. AIBS Bulletin 52: 19.

53. RN Treuhaft, BE Law, GP Asner (2004) High Spatial Resolution Remotely Sensed Data for Ecosystem Characterization. AIBS Bulletin 54(6): 511521.

54. X Zhou, NB Chang, S Li (2009) Applications of SAR Interferometry in Earth and Environmental Science Research. Sensors 9(3): 1876.

55. K Iizuka, R Tateishi (2015) Estimation of $\mathrm{CO}_{2}$ Sequestration by the Forests in Japan by Discriminating Precise Tree Age Category using Remote Sensing Techniques. Remote Sensing 7(11): 15082-15113.

56. SA Hall, IC Burke, DO Box, MR Kaufmann, JM Stoker (2005) Forest Ecology and Management 208: 189.

57. P Hyde, R Dubayah, W Walker, JB Blair, M Hofton, et al. (2006) Mapping forest structure for wildlife habitat analysis using multi-sensor(LiDAR, SAR/InSAR, ETM+, Quickbird) synergy. Remote Sensing of Environment 102: 63-73.

58. KS Lim, PM Treitz (2004) Estimation of above ground forest biomass from airborne discrete return laser scanner data using canopy-based quantile estimators. Scandinavian Journal of Forest Research 19: 558570 .

59. R Loos, O Niemann, F Visintini (2007) Our Common Borders Safety, Security, and the Environment Through Remote Sensing.

60. E N\a esset, T Økland (2007) Remote Sensing of Environment 79: 105.2

61. G Patenaude, RA Hill, R Milne, D L Gaveau, BBJ Briggs, et al. (2004) Remote Sensing of Environment 93: 368.

62. SC Popescu, RH Wynne, R F Nelson (2003) Canadian Journal of Remote Sensing 29: 564.

63. KJ Ranson, G Sun (1994) IEEE Transactions on Geoscience and Remote Sensing 32: 388.

64. H Saremi, L Kumar, C Stone, G Melville, R Turner (2014) Remote Sensing 6: 7592.

65. GA Wagner, DF Plusquellic (2018) Multi-frequency differential absorption LIDAR system for remote sensing of $\mathrm{CO}_{2}$ and $\mathrm{H}_{2} \mathrm{O}$ near 1.6 $\mu \mathrm{m}$. Applied Optics 26(15): 19420-19434. 